\title{
Metaphorical Expression of Bahasa Aceh in Trumon of South Aceh: Ecolinguistics Study
}

\author{
Nuzwaty $^{1}$, Aron Meko Mbete ${ }^{2}$, Eddy Setia ${ }^{3}$, T.Thirhaya Zein ${ }^{4}$ \\ ${ }^{1}$ Department of Linguistics, Post Graduate School, University of Sumatera Utara, Indonesia \\ ${ }^{2}$ Faculty of Culture Studies, University of UDAYANA Bali, Indonesia \\ ${ }^{3}$ Department of English Literature, Faculty of Culture Studies, University of Sumatera Utara, Indonesia \\ ${ }^{4}$ Department of China Literature, Faculty of Culture Studies, University of Sumatera Utara, Indonesia
}

\begin{abstract}
This study aims at describing metaphors of Bahasa Aceh that used by the language community in Trumon. The metaphorical frames are structured by forms of interaction of two models; a source and a target domain. The method employed was qualitative approach and the data obtained was from six informants who were born in Trumon, the range of the ages was from 35 to 60 years and they also married the locals. The numbers of metaphors are thirty pieces which commonly used as vernacular. In general, metaphors of Bahasa Aceh in Trumon constituted by the nature of flora and fauna that exist in local surroundings as the source domain, and human's behavior or his manner stands as the target domain. The source domain imposed some structure on the target by virtue of mapping that characterizing the metaphors. The relationship of both was processed in thought of the users, and also respected to the convention of the language community. In Trumon, star fruits are dried and called Asam Sunti and used as seasoning. No cook without asam sunti. Because of asam sunti is highly needed, placed it as a source domain which is associatively infer a generous person who is continuously help others. The words 'jih nyan asam sunti kamo (he is our asam sunti), convey metaphorical meaning 'he is the generous person who always gives his hand to help others'.
\end{abstract}

Keywords: metaphors, source domain, target domain, flora, fauna, convention, experience, thought

\section{Introduction}

Most of the time when people use language in joint activity, their talk runs along contextual foundation of their own creation and their own knowledge. This time they depend precisely on the assumption that the person with whom they are interacting share a similar understanding of the words they express, and make sense. Interaction with other person in everyday social situation provides people with ways of using language that they are continually able to appropriate and be able to adapt for later use. In using language to interpret their life people sometimes do not use literal meaning of words, but they use the metaphor ones.

It is a commonplace assumption that metaphor is a linguistic phenomenon, formulated as a language expression that is obviously not used literally and is recognized as a figurative expression. But it is not the only point to say, however metaphor is a language expression that is not only a phenomenon of linguistic, but at the same time it is a socio-cultural, neural and bodily experience as well. In other words, there is a close relationship between language and neural and body of the language users. As what Kovecses (2006:122), Cruse (2000:202), and Goatly (1997:1-3) express that, metaphor is a linguistic phenomenon, it exists in language merely because it exists in the body or brain and thought. Further, Kovecses (2006:130) remarks, metaphors are realized in socio-cultural reality and metaphors often define cultural models.

As a language device, metaphor involves two domains, they are source domain and target domain. The relationship between the two are caused either the two domains show some structural similarity or they are correlated in the member of the language speech community's experience. The source is more physical and the target is a more kind abstract of domain. The type of this correspondence is known as mapping.

In ecolinguistics point of view, metaphors are considered to fall under metaphor of ecology in the relationship between language and the natural environment of the language users. The history of the metaphor 'money is water', for instance, has illustrated how language adapts to new environmental condition, check (Fill and Peter 2001:5). Edward Sapir wrote 'Language and Environment' 1912, is an early attempt on the part of a linguists to go beyond the description of language in terms of sound system, word meanings, structure and the like to build a relation between nature and language. For Sapir, a lot of elements of human culture and language were ascribed to the influent of physical environment in which that culture is placed. Hence the interrelationship between the inhabitants of an ecology is governed by a number of factors, among others, tribes that live close to nature will speak their natural language. It means a language is influenced by the environment. So, different community might have different language and culture, and different languages will likely possess different metaphors, for they share different cultures which evoke distinct types of interpretations. 
The interrelationship between language and the environment of the language evokes the researcher's interest in looking in details at the forms of metaphors that are being used by the speech community in Trumon. Therefore the researcher attempts to investigate metaphorical expressions that are being used by the member of the language community of Acehnese Language (Bahasa Aceh) in Trumon. The research was done under the ecolinguistics perspective. Bahasa Aceh is one of the ethnic languages in Indonesia, and used as a medium of communication in the language community of Aceh. Aceh is one of the provinces in Indonesia, called Nanggroe Aceh Darussalam and is situated in the northern part of Sumatera Island, while Trumon is a small region in South Aceh which is surrounded by forest next to natural preserve Gunung Lauser. In Trumon culture, it is apparently not considered polite to engage in any direct requests for information. Therefore to understand cultural symbols and to interpret aspects of life, metaphors are commonly used. The metaphorical expressions, which are being used by the member of the speech community, have evidently been familiar for many generations.

Their knowledge of their own environment is full of information, which signifies their close relationship with the nature; the flora and the fauna. For the member of the speech community, the continually interrelationship and the interaction with ecological environment and ecosystem give space or opportunity for them to create metaphorical expression which convey not only socio-cultural meaning, but enrich the language as well. The formation of the metaphorical expression is commonly produced by cross mapping process from source domain to target domain. The source domain, which is more physical, stands as references and is derived from flora and fauna existing in Trumon and the target domain, the one which is more abstract conveying the aspects of human's life, and related to his behavior, manner or attitude as well. The connection between the two domains is established by some aspects of being similar that are connected and occupied neural structure in the brain.

A local expression like Meung hana angen, pane mumeet on kayee which can be literally translated into 'if trees sway, it is obviously caused by the presence of the wind blowing into it'. The expression acknowledges metaphorical meaning that underlies an event will not be occurred without a cause. The attendance of an event, a situation or a condition which expresses a natural phenomenon in which naturally happens, is recorded and stored in the brain of the member of the speech community, then reflected to their language in the creation of the metaphors being used.

\subsection{The Scope of the Study}

This research is directed towards the form of metaphors that provide the natural environment of flora, fauna, as references or source domain, and human's life with all of his characters as the target domain. The main focus of this study is on metaphorical expression as a linguistic phenomenon which is associated with the natural environment of Trumon (eco-regions). And it is concerned with the configuration of metaphorical expression that being used within the members of the speech community of Bahasa Aceh in Trumon. In other words, the metaphor discussed, merely covers the fundamental forms of metaphors in the social interactions.

The discussion is directed to analyzing and describing interrelationship of the natural environment that motivated the formation of metaphors being used by the language community in Trumon.

\section{Literature Review}

It has been mentioned above that this study utilizes ecolinguistic term to describe the formation of metaphors that are being used by the member of the language community in verbal interaction. Einar Haugen, one of the scholars who concerns on ecology of language (1972:326), revealed a definition of a language ecology as the study of interaction between any given language and its environment. The environment here is related to the society that uses the language as one of its code.

In his careful study under ecolinguistics perspective, Haugen discovered the usefulness of ecological parameters, like interrelationships, environment and diversity as some way link of language with ecology were brought together and established a branch of linguistics which was called ecolinguistic. He applied these parameters to his research on metaphor of ecology.

Ecolinguistics consider that language is a product of human activities and a part of social praxis. It is not only a social product of human activities, but at the same time it will change the human activities and social praxis as well. Bang \& Door (1990:5), in their point of view, that there is a dialectical relation between language and social praxis. The dialectical relation between language and social praxis, a language is dominated by social praxis, since it might be possible a social praxis without a language but it is impossible a language without a social praxis. So the dialectical relationship between language and social praxis are mutually exclusive. It means the investigation of a language at the same time is the investigation of human's social praxis. In another word the theory of language is a theory of social praxis as well.

In investigating a language, Bang \& Doors formulated linguistic theory in relation to dialectical theory of the social praxis. The theory is known as the Three-dimensionality of the social praxis. This theory accommodates three dimensions of social praxis; they are ideo-logical, bio-logical and socio-logical dimensions 
(Bang \& Doors 1995: 47). This three-dimensionality of the social praxis means that language is also a three dimensional element of social praxis. The ideological dimension is about human individual and collective mental, cognitive, and ideological systems. The sociological dimension is about the way people organize their interrelations in order to maintain a collectivity of individuals, like loving each other in a family and between friends, knowing each other between neighbors or in among tribes. Hence ecolonguistics is the study of interrelations of ideo-, socio-, bio-logical dimensions of language. The ecology and mental and social well-being of mankind go hand in hand, check (Lindo and Jeppe 2000:10-11)

\section{Methods Of Study}

This research was the field one which was taken place in Trumon, South Aceh. The method employed was qualitative approach, and data was obtained from six informants through recording activity. Even this research was field research but for supplementary information, the researcher make use of a collection paper of Hadih Maja (Hadih Maja is metaphor in local language), an unpublished book, written by one of the informants.

The setting was done in six interpersonal meeting at their home. In addition, ten participants helped the researcher to do the data cross checked. Either the informants or the participants were born and brought up in Trumon, and they all married with the locals. The range of the informants' ages was from 35 to 60 years. They came from a variety of educational and social backgrounds. Two informants and three participants work for the government, and one of the informants who wrote the Hadih Maja was an ex-headmaster of Trumon Secondary School. One of the participants is a midwife, and the others are famers and businessmen. The data analyzed and described was grouped in two. They are the group of flora and the group of fauna.

The data was as follows:

Table 1. Inventory of Data in The Group Of Flora

\begin{tabular}{|c|c|c|c|}
\hline & Source Domains & Metaphors & Gloss \\
\hline \multirow[t]{2}{*}{01} & $\begin{array}{l}\text { Boh Limeng Eungkot(Averrhoa } \\
\text { bilimbi) }\end{array}$ & & Star fruit \\
\hline & & Asam Sunti & The dried star fruit \\
\hline \multirow[b]{2}{*}{02} & Boh ara (Ficus racemosa) & & Tropical fig fruit \\
\hline & & Boh Ara Hanyot & The drifted tropical fig fruit \\
\hline \multirow{2}{*}{03} & Boh timon (cucumis sativus) & & Cucumber \\
\hline & & Boh Timon Bungkok & Camber cucumber \\
\hline \multirow[t]{2}{*}{04} & Camplie cina(capsicum frutescus) & & Local chili \\
\hline & & Peukeueng CamplieCina & To make the local chili hotter \\
\hline
\end{tabular}

Table 2. Inventory of Data in The Group of Fauna

\begin{tabular}{|l|l|l|l|}
\hline & \multicolumn{1}{|c|}{ Source Domains } & \multicolumn{1}{c|}{ Metaphor } & \multicolumn{1}{c|}{ Gloss } \\
\hline \hline & Abo (amphidromus perversus) & & Snail \\
\hline 1 & & Abo Udep Dua Pat & Snail survive in two area \\
\hline & Being (callinectes sapidus) & & Crab \\
\hline \hline & & Bieng Bak Babah Bubee & Crab in the mouth of bubu \\
\hline 3 & & & Cow \\
\hline
\end{tabular}

\section{Discussion And Result}

\subsection{Discussion}

Metaphors that are being used by the member of the speech community in Trumon are definitely invested the presence natural feature of flora and of fauna, that exist in the local surroundings environment. Either the natural feature of flora or of fauna are functioned as source domains and mapped in to all aspects of human's life as the target domain. The process of mapping is taken place in the mind and thought of the speech community based on ideological, biological, and sociological dimensions. All of the metaphors are conventionally conceived of as colloquial language.

The discussion is initially started from the group of flora that the source domains of the metaphors belong to, therefore the fauna will be after in the discussion. In this occasion, not all of the source domains will be discussed as a whole. The number of the source domains that being concerned on, is solely four in number 
from the flora group and three under the fauna one, which produce seven metaphors either. The reason of selecting these seven metaphor to come on the discussion are considered that all of these metaphors are the most common familiar ones which are continuously used in the social interaction and in the daily communication.

\subsubsection{The Group of Flora}

The first metaphor that will be discussed is Asam Sunti. Star fruit trees (averrhoa bilimbi) are planted in every single garden in Trumon. The fruits are dried called Asam Sunti and used as seasoning. No cook without asam sunti. The interrelationship of Asam Sunti with the community's need upon its seasoning, recorded and mapped in the mind and thought of the member of speech community through ideological and sociological dimensions. Because of this interrelation, in both human mind and social life, Asam Sunti was adopted into source domain and metaphor. The source domain is mapped into the target one that is a generous person who is continuously help others. The words 'jih nyan Asam Sunti kamo, is literally meant 'he is our asam sunti'. But, these words convey metaphorical meaning 'he is the generous person who always gives his hand to help and he is the person, whom we ask some advices. Metaphor of Asam Sunti is being used conventionally.

The second metaphor that will be discussed is Boh Ara Hanyot. This metaphor is generated from a source domain, Boh Ara (ficus racemosa). Boh Ara is recognized as tropical fig fruit, and hanyot means drifted and carried by the stream. The tropical fig trees grow along way of the bank of a small river nearby. When the season comes, the old fruit usually drop into the river floating in the surface one after the other and at last they are carried by the stream. In the local language, this situation is called boh ara hanyot. Unlike other fruits, the fruit season of this kind fruit is unpredictable. The members of the community who live on the farm downstream are fully aware of this kind of seasons, since these fruits are really useful for health and traditionally the people use these ones as medicine.

The unpredictable season of boh ara, is truly being relation with the exact time when the fruits are drifted. This situation is really understandable and occupied both the people's mind and social praxis. By this kind of situation, the people created a metaphor Boh Ara Hanyot to attribute an unpredictable time. The utterance that might be expressed by a mother to her daughter who is waiting for an un fulfill promise, made by her friend. Bek kah preh Boh Ara Hanyot which is literally meant 'please don't wait the tropical fig fruit drifted and carried by the stream'. But metaphorically this statement convey the meaning of 'please don't wait, it will be vain to do'. For this metaphor source domain is occupied by Boh Ara mapped on to target domain that is unpredictable time.

The third one is metaphor of Boh Timon Bungkok. The source domain of this metaphor is boh timon (cucumis sativus), it is cucumber in English. Bungkok means humped or crooked. Boh timon bungkok could be translated in to crooked or humped cucumber. The people of Trumon, recognize the biological character of these fruits, a cucumber be a humped one definitely depends on the physical environment condition, for instance it is respected to the little amount of rain fall in dry season. Economically this kind of fruit is not sold well and the farmers will gain less profit than usual, and the community regards this as an unexpected condition.

The unexpected condition that the farmers have through dimensions of social praxis posit Boh Timon Bungkok as a reference, and occupy the source domain of metaphor Boh Timon Bungkok which is mapped on to a target domain. The target domain of this metaphor is a condition of a fisherman, who has caught a small number of fishes which is reflected to his outcome. The condition happens, usually caused by the unstable condition of the weather. When a fisherman says an utterance, Uro nyo Boh Timon Bungkok, literally it could be translated into 'today is a humped cucumber'. Uro means 'day' and nyo means 'this'. Metaphorically this utterance conveyed detriment. The addressee will capture that the speaker (the fisherman) is not being happy because he did not get many fishes.

The last one that will be discussed is metaphor of Pe keeng Camplie Cina. This metaphor is created from source domain Camplie Cina. Camplie Cina is a local chili (Capsicum frutescens) and the taste is biologically extremely hot. The source domain, Camlie Cina is motivated by embodied experiences of the speech community through biological and sociological dimensions, and based on human's sense of taste. Because of its nature taste, this chili stands as a source domain mapped to the target domain that is one, whom identified as a clever and smart person. The interrelationship between the two domains, which is located in both social life and human mind, produced a metaphor Pe keeng Camplie Cina. The words pe keeng mean 'to make hotter'. Therefore words pe keeng camplie cina are literally meant 'to make the chili hotter'.

Biologically this local chili is naturally hot, so it will not be able to make it hotter and it is impossible to do it, moreover it will be a fool to do that thing. The words pe keeng camplie cina convey a metaphorical expression which is conventionally used to denote an impolite attitude to teach a smart or a clever person. In the social interaction, the smart persons are definitely respected because he is regarded knowing every things. So it is not accustom to teach them. The common utterance which speech community expressed bek kah pe keeng boh 
campli cina (you don't need to make the chili hotter). This utterance conveys metaphorical meaning as 'please don't teach him, it is not polite to do so'. This metaphorical expression is commonly addressed to a person who tries to teach another man who is more clever than him.

\subsubsection{The Group of Fauna}

The first that will be discussed is metaphor of Abo Udep Dua Pat. This metaphor is generated from source domain abo (amphidromus perversus), that is snail which is commonly found a lot on the beach of Trumon. Abo Udep Dua Pat can be literally translated into 'a snail can live or survive in two kinds of environments'. Udep means 'live', dua means 'two', pat means 'place'. Biologically this kind of snails is under the amphibian species. So it can survive in the water and on the ground place, especially on the sand.

The language community really recognizes the characteristic of this creature, which is naturally being able to stay in two totally distinct areas. And the condition of the creature's life, by the language community was place as a source domain which evoked a metaphor; Abo Udep Dua Pat which is mapped on to the target domain that is a good manner person who has positive attitudes on making friends with any one from any levels of social background, and he gives much attention to the destitute ones. The interrelation between Abo Udep Dua Pat and the person, who has good manner in the social intercourse, is stored in either in the mind or thought of the member of the speech community and on the dimensions of social praxis.

The second metaphor will be discussed that classified under the group of fauna is Bieng Bak Babah Bubee. Bak means 'at' babah means 'mouth or 'entrance'; bieng means 'crab' (callinectes svidus); bubee is hollow vessel traditional equipment used by a local fisherman to catch fish.

There is a great deal of fish found in the swamp of Trumon. The activity of catching the fish is done by using the vessel. The fisherman put this equipment to bottom of a swamp and the fish will go inside through the entrance. After leaving it a night, they commonly take the vessel out early in the morning and gain much fish. Unluckily, sometimes none of fish is in the vessel and the fisherman gets lost. This usually happens because of the blocking entrance done by a crab. It is called Bieng Bak Babah Bubee. The situation which is heavily faced by the fisherman, take the community's attention in social intercourse and into dimension of social praxis and produce a metaphor Bieng Bak Babah Bubee. Bieng stands as a source domain is mapped to a bad attitude of someone as a target domain.

Metaphor of Bieng Bak Babah Bubee can literally be translated into a crab is at the entrance of a vessel (block the entrance of the vessel). Metaphorically Bieng Bak Babah Bubee is identified and transferred to a bad attitude of a person who has an attempt to waylay or to hamper another one's job. Because of this, the one whom has been hampered gets much lost.

The last metaphor will be discussed that classified under the group of fauna is metaphor of Leumo Rot Iboh. This metaphor is supported by a source domain, leumo means 'cow' (auerochse). A great number of cows are found in this place. The owners are quite rare to provide corrals for the cows. These animals survive in an open air and go here and there. They commonly graze iboh, which grows at around the swamp. Iboh is a small green leave of nipa palm. Cows like gazing iboh and when they graze these leaves, it sounds noisily and tumultuously.

The people saw this and heard the voice, placed Leumo as a reference or a source domain to create a metaphor, Leumo Rot Iboh which literally can be translated into 'cows graze small green leave of nipa'. The target domain of this metaphor is a person who always speaks rudely and hurt others' feelings. The interrelation is linked the sounds producing while grazing to an unfriendly person. The relationship between the two is located on the brain.

\subsection{Result}

So far we have been talking about the metaphors that are being used by the member of the language speech of Bahasa Aceh in Trumon. These metaphors can be recognized as conventional metaphors, since the forms are created by the relationship of dimensions of social praxis and will have to be negotiated in the process of mental collective of the speech community. The source domains of the metaphors are derived from the biological characteristic of flora and fauna of Trumon surroundings, mapped on to human and his manner as the target domains.

\section{Conclusion}

From this research can be drawn an inference that the metaphorical expression being used by the member of the speech community of Bahasa Aceh in Trumon are structured by forms of interaction of two models; a source and a target domain. The source domains are formulated and generated from the characteristic of the nature of flora and fauna that grow or exist in local surroundings or in physical environment as well. The target domains are occupied by either human aspect of life, or human's behavior or his manner. The source domain imposed some structure on the target by virtue of mapping that characterizing the metaphors. 
The interrelationship between the two domains is supported by a kind of link of human's mind and thought with the dimensions of social praxis. Almost all of the metaphors were obviously generated from either the language community's experience that happens on daily interaction reflected to their social life and the member of the speech community's convention.

\section{References}

[1]. Kovecses, Zoltan. 2006. Languange, Mind, And Culture: A Practical Introduction. New York: Oxford University Press.

[2]. Cruse, D Alan. 2000. Meaning in Language: An Introduction to Semantics and Pragmatics. New York: Oxford University Press.

[3]. Goatly, Andrew. 1997. The Language Of Metaphors. London and New York: Routledge.

[4]. Fill, Alwin dan Peter Muhlhausler (Eds). 2001. The Ecolinguistics Reader: Language, Ecology, and Environment. London and New York: Continuum.

[5]. Haugen, Einer. 1972.The Ecology of Language. Standford, CA: Standford University Press.

[6]. Lndo, Anna Vibeke dan Jeppe Bundsgaard. 2000. Dialectical Ecolinguistics: Three Essays For The Symposium 30 Years of Language and Ecology in Graz December 2000. Odense: University of Udense. Research Group for Ecology, Language and Ideology Nordisk Institut. 